Proceedings

\title{
Distinctly Altered Forest Structure Decreases the Predicted Probability of Breeding in Small Passerines Occupying Great Spotted Woodpecker Cavities
}

\author{
Jan Hanzelka ${ }^{1,2}$ *, Daniele Baroni ${ }^{2}$ and Toni Laaksonen ${ }^{2}$ \\ 1 Institute for Environmental Studies, Faculty of Science, Charles University, Benátská 2, 12801 Prague, Czech Republic; \\ email1@gmail.com (J.H.) \\ 2 Department of Biology, Faculty of Science, University of Turku, Vesilinnantie 5, 20014 Turku, Finland; email2@gmail.com \\ (D.B.); email3@gmail.com (T.L.) \\ * Correspondence: jan.hanzelka@natur.cuni.cz \\ † Presented at the 1st International Electronic Conference on Biological Diversity, Ecology and Evolution, 15-31 March 2021; \\ Available online: https://bdee2021.sciforum.net/.
}

\begin{abstract}
Ecological functioning of boreal forests has been impacted by forest management practices reshaping the structure of forest habitats and substantially defining the tree species composition. An ongoing adverse development could alter links of many ecological chains, from which we focused on the relationship between primary and secondary cavity nesting birds. Great spotted woodpecker (GSW) symbolizes a principal cavity excavator being affected by forest management in its choice of available nesting trees. Its cavities are further used for breeding of small passerines, which can favour a specific forest structure around their nests. To investigate which structure could be preferred, we have searched for breeding events in blue and great tit in $760 \mathrm{~km} 2$ area of managed boreal forests in southwest Finland in 2018-2020. Using species distribution modelling approach we have modelled the probability of breeding in blue and great tits based on high resolution forest parameter maps provided by Natural Resource Institute Finland. We have selected three uncorrelated variables - mean tree stand volume of Scots pine, spruce, and broad-leaved trees and updated the layers by logging areas in respective years. The resulting raster map showed higher (50-70\%) and low (0-20\%) probability of predicted breeding for $25 \%$ and $29 \%$ of the forest area, respectively, though the probability estimates greatly varied especially of the preferred area. The low-breeding probability areas nicely overlapped with young and recent clearings, having much lower mean volume of spruce and Scots pine, but higher volume of broad-leaved trees than potentially preferred areas. Because GSW breeds overwhelmingly in aspen trees, including trees left in clearings, within the study area, it suggests that despite the presence of retention trees these significantly altered forest areas can be of lower importance regarding the breeding of some secondary cavity nesters.
\end{abstract}

Keywords: aspen; boreal forest; cavity nesting birds; forest management; Scots pine; species distribution modelling; spruce

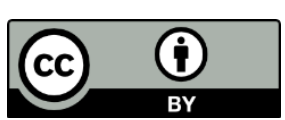

(C) 2020 by the authors. Submitted for possible open access publication under the terms and conditions of the Creative Commons Attribution (CC BY) license (http://creativecommons.org/licenses/by/4.0/). 